\title{
Impact of the financial crisis on COPD burden: Greece as a case study
}

\author{
Ourania S. Kotsiou ${ }^{1}$, Spyridon Zouridis ${ }^{2}$, Marinos Kosmopoulos ${ }^{2}$ and \\ Konstantinos I. Gourgoulianis ${ }^{1}$
}

Affiliations: ${ }^{1}$ Dept of Respiratory Medicine, Faculty of Medicine, University of Thessaly, BIOPOLIS, Larissa, Greece. ${ }^{2}$ Faculty of Medicine, National and Kapodistrian University of Athens, Panepistimiopolis, Athens, Greece.

Correspondence: Ourania S. Kotsiou, Dept of Respiratory Medicine, University of Thessaly, Faculty of Medicine, BIOPOLIS, 41500, Larissa, Greece. E-mail: raniakotsioudgmail.com

@ERSpublications

Greece has been suffering a high burden of COPD, which has profoundly deteriorated due to the economic crisis http://ow.ly/eXc030hf934

Cite this article as: Kotsiou OS, Zouridis S, Kosmopoulos M, et al. Impact of the financial crisis on COPD burden: Greece as a case study. Eur Respir Rev 2018; 27: 170106 [https://doi.org/10.1183/16000617.01062017].

ABSTRACT Poverty and low socioeconomic status have been associated with chronic obstructive pulmonary disease (COPD). The current financial crisis has forced millions back into poverty. Greece is one of the countries hit the hardest, and is in the middle of a deep ongoing collapse. There have been early reports stating the apparent effects of the Greek downturn on respiratory health. This review summarises the overall impact of the financial crisis on COPD burden throughout the period of economic downturn by analysing the case study of Greece. In all levels of the healthcare system, current economic restrictions have reduced the capacity to prevent, diagnose and treat COPD in parallel with current higher detection rates of COPD. Remarkably, expenditure on healthcare has been reduced by $>25 \%$, resulting in major healthcare equipment shortages. Lower wages (by up to $20 \%$ ) and higher co-payments of up to $25 \%$ of a drug's purchase price have led to patients struggling to afford inhaled medications. Treatment nonadherence has been reported, resulting in $11.5 \%$ more exacerbations and $14.1 \%$ more hospitalisations annually, while the mean cost per severe COPD exacerbation has been approximated as $€ 2600$. Greece is a noteworthy example illustrating how COPD burden, quality of care and patients' outcome can be affected by economic crisis.

\section{Introduction}

Greece is in the middle of a deep and ongoing financial crisis that began in November 2009, but deepened after the implementation of austerity measures in early 2010 [1]. It is already known that economic recession in a country may have a severe impact on the psychological wellbeing of the population due to general stress, changes in personal life and the anticipation of job loss [2]. It has been suggested that the current Greek recession may act as a precipitator, in combination with other risk factors such as the presence of a chronic or mental illness, for suicide risk [3]. The possibility of harm in coronary health in vulnerable individuals cannot be ruled out [4]. Economic downturns have historically been associated with increases in all-cause mortality [5-8]. In the Greek population, early reports have suggested a negative effect of financial crisis on public health [3, 9-12], and remarkably on respiratory health [1, 9, 10, 13-15]. The impact of the Greek downturn on respiratory health was apparent even though most studies used data

Received: Sept 142017 | Accepted: Oct 162017

Conflict of interest: None declared.

Provenance: Submitted article, peer reviewed.

Copyright OERS 2018. ERR articles are open access and distributed under the terms of the Creative Commons Attribution Non-Commercial Licence 4.0. 
covering only the first years of the crisis and reported its short-term effects [16]. This article summarises the overall impact of the financial crisis on chronic obstructive pulmonary disease (COPD) burden throughout the period of economic downturn, analysing the case study of Greece. A computer-based search of the English literature was performed in PubMed and Scopus. The considerable body of information examined in this article includes epidemiological data, to a large extent, but not exclusively, presented in Greek studies.

\section{Estimating the global burden of COPD: prologue of a thorny and arduous problem}

COPD is a leading cause of morbidity and mortality on a global scale. The prevalence of COPD has been estimated to be approximately 210 million cases worldwide [17]. However, a recent consensus has increased this estimate to 328 million individuals [18], while some reports suggest there are now 600 million cases [19]. COPD is the attributed cause of 2.9 million deaths, making it the third leading cause of mortality behind cardiovascular disease and cancer [20]. However, there appears to be great variance in COPD prevalence among countries, as supported by provincial prevalence estimates. In fact, with an estimated world prevalence of $9.2 \%$, in countries of Latin America a mean $13.4 \%$ of the population is diagnosed with COPD [21] compared to $\sim 6 \%$ in the USA [22, 23] and $8.6 \%$ in Japan [24]. In Europe there is also high variability among studies, with estimates ranging from $4 \%$ to $10.2 \%[17,25]$, while current data point to a probable value of $\sim 3 \%$ [25]. However, irrespective of world region and independent of prevalence within a region, COPD is substantially underdiagnosed, with only about 10$15 \%$ of all cases identified globally [26], while the rest elude diagnosis and early intervention [26]. Underuse of spirometry and incorrectly performed or interpreted spirometry tests seem to be the reasons for such a high rate of under/misdiagnosis [27].

\section{Investigating pre- and post-crisis prevalence of COPD in Greece}

In Greece during the years before the financial crisis, only a few studies had provided prevalence estimates for COPD. At the start of the 21 st century only three studies had presented epidemiological data, but none had used a standard definition to diagnose COPD, and the reported prevalence ranged from $9.6 \%$ to $17.1 \%$ [28-30]. Another study conducted between March and May 2001 estimated that the overall COPD prevalence in the population aged $>35$ years with a smoking history of $>100$ cigarettes per lifetime was $\sim 8.4 \%$ [31]. A study published 1 year later, performed in northern Greece and including the population over an extended age range, reported a lower COPD prevalence rate of 5.6\% [32]. One of the latest studies conducted before the Greek crisis began (from January 2006 to June 2007) included 15 primary healthcare centres in central Greece and documented a prevalence rate of $18.4 \%$ [33]. In contrast, a report from Cyprus found a lower COPD prevalence of $4.9 \%$ in 2008 [34]. The variations observed in the prevalence rates were mainly due to differences in the diagnostic methods (symptoms, physician reports and spirometry) as data of comparable methodologies were lacking (definition of COPD, age and sex distribution and other population characteristics evaluated in each study).

In the years following the financial crisis only three studies were performed. The first was a nationwide Greek study (October 2010 to March 2011), which recorded a prevalence rate of $18.2 \%$ [35]. The second, conducted in the same period, showed similar prevalence rates of $20.2 \%$ in females and $17.1 \%$ in males [36]. The third was a random nationwide digit-dialled telephone survey conducted in 2015 , which found a self-reported COPD prevalence of $10.6 \%$ [37].

Although there were obvious methodological differences, an increasing COPD prevalence rate seems to be apparent within the past 10 years, although high COPD prevalence rates are to be expected considering the high smoking rates in Greece compared with other European Union (EU) countries, as well as the rest of the world [17].

\section{Investigating the pre- and post-crisis geographic distribution of COPD in Greece}

The prevalence of COPD in Athens before the crisis was reported to be $\sim 6 \%$, while in other urban areas (defined as cities with a population $>10000$ people) it was estimated to be higher (10.1\%) [31]. Specifically, it was reported that $>50 \%$ of COPD patients lived in Athens or other urban areas [31]. Similarly, a study performed after the onset of the economic crisis found that $32.5 \%$ of newly diagnosed COPD patients were living in Athens and 32\% in other urban areas [35]. A proposed explanation for this geographic variation in COPD rates is the limited access to spirometry in rural areas of Greece, which is strongly evident before and after the crisis [33]. It is well documented that in primary healthcare settings in Greece there are a lack of specialised pulmonologists to perform spirometry, as well as a lack of training and feedback in diagnostic spirometry for general practitioners, both of which are major barriers to spirometry use [38-41]. Thus, the percentage of undiagnosed patients in primary healthcare settings is estimated to be very high, both pre- [33,39] and post-crisis [38, 40, 41]. Notably, the study of SpYratos et al. [38] reported that $52.6 \%$ of COPD cases remained undiagnosed. 
Additionally, outdoor and indoor air pollution (such as second-hand smoking) experienced by populations living in urban areas is associated with the development of COPD. Both contribute substantially to the global burden of disease [42]. It also appears that outdoor air pollution is a significant environmental trigger for acute exacerbations of COPD, leading to increasing symptoms, emergency department visits, hospital admissions and even mortality [43]. In 2015, the proportion of deaths (due to COPD, lung cancer and lower respiratory infections) attributable to ozone in Greece was estimated to be $\geqslant 2.60$ per 100000 people, among the highest globally [44]. Surprisingly, improvements in overall air quality have been reported by PARASKEVOPOUlou et al. [45], who took recordings in a 5-year period following the crisis (May 2008 to April 2013) of the concentrations of major pollutants, such as particles with a $50 \%$ cut-off aerodynamic diameter of $2.5 \mu \mathrm{m}$ and $10 \mu \mathrm{m}$ and sulfate, which declined rapidly in urban areas such as Athens $[1,45]$. Low economic and industrial activity during the financial crisis has contributed to this decrease in air pollution [45]. Improvements in overall air quality are likely to have an important effect on COPD burden in the future.

\section{Profile of COPD patients in Greece during the crisis}

A number of studies have shown that COPD has been more prevalent among smokers, older adults and males in Greece [31-33, 35]. COPD patients have displayed this profile both pre-crisis and throughout the crisis period. Tobacco smoking has clearly been shown to be the major environmental risk factor predisposing to the development of COPD, and a definite link has been established between the two entities. According to Greek data, $81.3 \%$ of COPD patients reported smoking for $>15$ pack-years [31, 46] and only $10.2 \%$ of COPD patients were classified as never-smokers [35].

As well as smoking intensity, age is also significantly associated with higher COPD prevalence in both men and women [31]. There is a linear increase in COPD prevalence with patients age [25, 31-33]. The average age of COPD patients across studies was 71 and 68 years for the pre- [33] and post-crisis period [35], respectively. Comparably, global estimates have reported that $40 \%$ of patients are aged $40-60$ years and $30 \%$ are aged $>60$ years [25].

Both sexes seem to be affected, but with a higher prevalence in males [31-33, 35, 47]. In the pre-crisis period $73.3 \%$ of COPD patients in Greece were reported to be males [31], while the sex-standardised COPD prevalence was $11.6 \%$ for men and $4.8 \%$ for women [31]. Analogous results were obtained from a study conducted in northern Greece, in which the prevalence of COPD in males was shown to be $8.2 \%$ and in females was 2.5\% [32]. Likewise during the crisis, Mitsiki et al. [35] estimated that the male to female ratio in Greece was 2.5:1 and another study conducted in 2010 in Thessaly (central Greece) in 2010 found that women represented $12.5 \%$ of COPD patients [33].

Additionally, other sex-related differences in the Greek COPD population were recorded after the onset of the crisis [36]. Notably, it was highlighted that female patients tended to present at an earlier stage of COPD and had more comorbidities than male patients [36]. Consistently, it was documented that women had a 1.040-fold higher risk of having a cardiovascular disease than men [48]. Moreover, female patients seemed to be younger and presented with a less severe stage of disease compared with males $(24.6 \%$ and $13.3 \%$ of female patients and $17.2 \%$ and $22.1 \%$ of male patients were classified at Global Initiative for Chronic Obstructive Lung Disease (GOLD) stage I and IV, respectively), and attended more outpatient visits [36].

Certain patient groups among the Greek population also present with a high vulnerability to COPD development, including former employees within the shipbuilding industry, for whom COPD prevalence is $\sim 13 \%$ [49].

\section{Socioeconomic status and COPD}

Many other factors have been linked to increased risk of COPD development. Adjustment of patients according to educational level showed lower disease prevalence in the population with a higher educational level $[41,50]$. This is similar to the results from a Danish study, which found that university graduates and people with $\geqslant 10$ years of education presented lower rates of disease compared to those with $<10$ years of education [51]. In particular, a significant interplay seems to exist between COPD and socioeconomic status [52-57]. A significant negative correlation between lung function (primarily forced expiratory volume in $1 \mathrm{~s}$ and forced vital capacity) and socioeconomic status has been established [54]. A relationship exists even after adjusting for smoking status, occupational exposure and race [54]. Smoking is associated with a greater absolute mortality risk due to lung cancer or COPD for individuals in lower socioeconomic groups [55-58]. Income is inversely associated with COPD treatment initiation [57]. People with low income are also diagnosed with more severe stages of COPD and are more likely to be hospitalised [58]. Moreover, it was found that low socioeconomic status is a major factor associated with chronic diseases and negatively affects access to healthcare services [14]. Decreased wages (by 20\%) and increased unemployment (from $9.6 \%$ to $26.5 \%$ ) [1], both consequences of the ongoing international economic 
turmoil, are the main reasons for the difficulties in access to healthcare services $[10,14]$. There is little information concerning the broader term socioeconomic status of patients with COPD in Greece. Only one study has reported that most COPD patients were retired, had a low educational level and low monthly income [59]. The majority came from the same social class, as indicated by similarities in their monthly income, their previous jobs and education level [59].

\section{Respiratory mortality in Greece amid an economic crisis}

Early reports from Greece have demonstrated a negative effect of the financial crisis on respiratory health, resulting in increases in poor self-rated health [60], all-cause mortality $[1,5,10,61]$, outbreaks of infectious diseases $[1,12]$, restrictions in access to healthcare $[1,11,12,60,62]$ and mortality due to adverse events during medical treatment [61]. In terms of the number of years of life lost due to premature death in Greece, international reports found that from 2010 to 2015 COPD rose from the seventh to the fifth leading cause of premature death. In 2015, COPD was associated with 241.4 years of life lost among 100000 individuals (all sexes), which was, however, considerably lower than the national average [63]. Additionally, a recent Greek study has reported that mortality from respiratory diseases has declined during the crisis, in contrast with its increasing trend before 2009 [1] (with the exception of 2015, which showed an increase in all-cause mortality [1]). Standardised mortality from all diseases of the respiratory system has decreased at an average rate of 3.2\% per year during the crisis (97.1 per 100000 in 2009 and 84.9 per 100000 in 2013), in contrast to an average annual increase of $3.3 \%$ in the pre-crisis period (75.7 per 100000 in 2001 and 97.1 per 100000 in 2009) [1]. The sharp decline in mortality from respiratory diseases observed until 2013 could be interpreted as an early sign of smoking reduction [1] and increased physical activity levels [1]. However, the increase of respiratory mortality in 2015 indicated that factors influencing respiratory mortality may be more complex [1]. Analogous results have been obtained previously by TAPIA GRANADOS and IONIDES [64], who reported that all-cause and respiratory mortality reductions in 2007-2010 were considerably larger than in 2004-2007. On the basis of the generalised European experience of the past 20 years, recessions, on average, have a beneficial short-term effect on the mortality of the adult population [64]. However, conflicting studies have indicated that economic downturns are historically associated with increases in mortality, mainly attributable to psychosocial stress due to unemployment [65] or intentional violence [6].

\section{Primary prevention of COPD in the years of economic crisis}

COPD is becoming the scourge of modern society. Therefore, it is essential to develop efficient methods for primary prevention, early diagnosis and access to treatment in order to limit stage progression and disease exacerbations. Despite the significance of the aforementioned goals, their implementation in the Greek healthcare system in the case of COPD has not been satisfactory during the current turmoil.

Regarding the primary prevention of COPD, the main preventive measures are smoking avoidance and cessation. However, Greece is a leading tobacco-producing country in the context of the EU. It had the highest rate of tobacco consumption in the EU in 2010 [66, 67], at 2458 cigarettes per capita [67]. In subsequent nationwide studies the prevalence of smoking was estimated to be $42.6 \%, 41 \%, 38.1 \%$ and $38.2 \%$ in 2008, 2010, 2011 and 2013, respectively [46, 67, 68]. Similarly, according to estimates of the European Commission for 2015, approximately three-quarters of daily Greek smokers revealed high smoking frequency (>15 cigarettes per day), while $24.8 \%$ of daily Greek smokers reported smoking $\geqslant 25$ cigarettes per day [48,67]. A recently published study has estimated that the prevalence of current smoking in Greece among women (25.7\%) is by far the highest among all European countries [67, 69] and considerably higher among the youngest age groups $[67,70]$. Specifically, the prevalence of smoking was quite low among the population aged $\geqslant 65$ years before the crisis and this has not changed in recent years [1]. Furthermore, according to a study conducted in the midst of the crisis, the prevalence of current smoking was found to increase with higher levels of education, especially in women, which is in contrast to the patterns of smoking in the West $[67,71]$. It is well known that in the western social context smoking is more prevalent among individuals with lower education [67, 71]. The data from RACHIOTIS et al. [67] supported the findings that in western countries lower educated people smoked more than higher educated people. The data obtained by CAVELAARS et al. [71] documented that the highest odds ratios among less educated younger men were observed in Norway, Sweden, France and Great Britain, whereas among less educated older men the highest odds ratios were observed in Great Britain and Norway. Furthermore, this finding cannot explain the higher reported prevalence rates of COPD in lower educational levels $[42,50,51,59]$. Thus, tobacco prevention strategies should mainly target these smoking groups [67]. Generally, a shift towards less healthy behaviour was noticeable after the economic crisis, as has been observed in two recent Greek studies [72, 73].

On the contrary, other data has documented that, in Greece, tobacco consumption has declined sharply [ 1 , $46,48,50,68]$. Specifically, the studies show that the prevalence of smoking declined from $42 \%$ to $38 \%$ 
with 540000 fewer adult smokers in 2015 compared to 2008 [1, 50, 68], and annual cigarette consumption per capita decreased by $37.5 \%$ between 2009 and 2014, dropping from 3.164 to 1.979 cigarettes, a change mostly achieved within the first couple of years $[1,46,50,68]$. Therefore, the overall population exposure to smoking during the crisis is likely to be much lower than previously reported, despite poor enforcement of tobacco control measures by successive Greek governments $[1,68]$. The conflicting data on this issue highlight subject matter for further investigation in Greece.

But what is generally known regarding smoking behaviour during economic strain? The literature regarding this topic is an assortment of opposing data. It is supported historically that economic downturns are associated with higher rates of morbidity, all-cause mortality and poorer health status [3, 68, 74-79]. The association between economic turmoil as a destructive health promoter that leads to high cigarette smoking rates is a matter of debate $[3,6-8,10,74-79]$. Economic collapse, through a detrimental impact on the employment sector, by lowering lower-paid employees' wages and increasing unemployment, may lead to a shift towards less healthy lifestyle choices such as smoking [74-79]. It has been found that there is a noticeable decline in the happiness levels in countries that are hit hard by recession, so a sovereign debt crisis may affect smoking behaviour [74-79]. Smokers may be citing an increase in perceived stress to justify their relapse or failure to quit, and they are unable to quit their ongoing behaviour because of the offsetting increase in stress, thus falling into a vicious circle [74-79]. However, other studies have reported that economic recession is associated with a decline in the prevalence of cigarette smoking [1] and that a crisis may be health promoting [68, 80-82]. The effects on smoking behaviour appear to be largely influenced by price increases [1]. Reduced disposable income has been the main driver of this decline potentially leading to a significant long-term health gain [1], as it has transformed cigarettes into luxury goods $[1,81]$. Additional research in that direction actually characterises cigarette smoking as a cause of stress and, furthermore, smoking cessation as a valuable way to break the stress cycle [80-83]. Finally, a former smoker who experiences a drop in income may be less tempted to start smoking again because of the reduced affordability of cigarettes [84, 85].

It has been reported that even a brief 3-min period of counselling urging a smoker to quit can be effective and should be conducted by a healthcare provider, as a minimum [36, 86, 87]. Smoking cessation counselling in primary care accounts for $9 \%$ of patients with COPD quitting smoking; however, if no intervention takes place this decreases to $4 \%[36,87]$. Furthermore, regarding smoking cessation, a notable difference is found when looking at the education level of smokers. Those with the lowest educational level (primary or less) have the highest percentage of quitting (61.0\%) [50]. However, recently published work has reported that the majority of patients are still smoking at the time of diagnosis and $30-50 \%$ of COPD patients keep smoking after diagnosis [87].

Moreover, Greece is among 10 countries in the World Health Organization European Region to have introduced comprehensive policies for smoke-free public areas [46]. At the same time, findings show that exposure to smoking in public places remained very high during the crisis [46]. Implementation of existing smoke-free legislation has been inconsistent and the majority of the population is regularly exposed to second-hand smoke [46]. It is noteworthy that more than nine out of 10 individuals are exposed to second-hand smoke when visiting bars/nightclubs, more than seven out of 10 are exposed when visiting restaurants [67], and more than half of those who work indoors are exposed [46, 88]. In total, $90 \%$ of the Greek population is exposed to tobacco smoke (current smoking and second-hand smoke) [67].

\section{Secondary prevention of COPD in the years of economic crisis}

Secondary prevention aims to detect airway obstruction when it is still relatively mild and treatable [89]. Studies focusing on Greek primary healthcare settings reveal that COPD is mainly undiagnosed [33, 38-41, 90]. Ideally, approaches to achieve the goal of early diagnosis in COPD need a major overhaul, and a culture change is required in primary-care settings. For this reason, a higher index of suspicion, as well as wider use of spirometry for diagnosis, are proposed [33, 38-41, 89-91]. A study conducted at the beginning of the economic recession revealed major shortages in rural primary healthcare equipment; only $4.6 \%$ of rural doctors had spirometers available for clinical use [91]. Moreover, Greece has high variability in the distribution of pulmonologists, and therefore significantly different rates may be observed among regions, independent of population risk factors [35]. Interestingly, a positive correlation has been reported between COPD diagnosis and private care settings [35], probably due to the lack of equipment and/or specialised pulmonologists in the Greek public healthcare system [92]. In 2011 there were reports of a $40 \%$ reduction in public hospital budgets, while between 2009 and 2014 total health expenditure fell from 10.1\% of the gross domestic product to $6 \%$, a decrease of $>25 \%$ [92-95].

Crucially, an alarming pattern emerges from the comparison of COPD prevalence in the insured population and general population estimates. The use of data from EOPYY (National Organization for 
Healthcare Services Provision) revealed 174357 patients on COPD treatment, compared to the total number of almost 9.9 million who were reported to be insured in 2011 [13, 96, 97]. It is worth mentioning that 2 million patients were thereafter excluded from public insurance and, thus, could not access mainstream healthcare services. This fact has important clinical implications regarding non-diagnosis and no treatment of COPD [11-13, 96, 97].

\section{Tertiary prevention of COPD in the years of economic crisis}

Tertiary prevention is paramount to monitor and manage symptoms with proper treatment, prevent relapse, and promote health and functioning in patients with COPD. Thus, in the vulnerable post-diagnosis phase, aftercare and follow-up aim to stabilise treatment effects and prevent relapse or re-admission. Barriers to healthcare access have emerged as one of the main negative consequences of austerity, as the proportion of Greek adults who reported unmet healthcare needs more than doubled in just 5 years, with $12.2 \%$ of respondents citing cost as the main reason for not receiving treatment or diagnostic tests [14, 15, 95]. Furthermore, from 2009 onwards, public pharmaceutical expenditure followed a downward trend, from approximately $€ 5.3$ billion in 2009 to approximately $€ 2$ billion in 2014 , notably by cutting the prices paid for drugs and promoting the increased use of generics [14, 93-95]. At the same time, average out-of-pocket expenditure almost doubled between 2010 and 2015, mostly attributed to increased cost-sharing rates for prescription drugs and healthcare services, either as user fees for public services or increasing use of private services [14, 93-95]. This suggests that unmet healthcare needs increased after the enactment of austerity measures in Greece, mainly due to patients' difficulty in covering the costs of medical care [98].

\section{Treatment adherence during crisis}

One of the most important issues facing Greek society is the poor adherence of both physicians and patients to COPD treatment. Over the past few years it has been demonstrated that clinical practitioners deviate significantly from GOLD guidelines for COPD management $[99,100]$. Recent studies have shown overtreatment in the early stages of COPD, with only approximately half of patients treated according to GOLD guidelines $[35,38,99,100]$. The combination of long-acting $\beta$-agonists/inhaled corticosteroids has the highest prescription rates and absorbs most of the pharmaceutical expenditure for COPD [99, 100]. Moreover, a cumulative $44.8 \%$ of patients are treated with triple COPD treatment [99, 100]. In other words, adherence to treatment differs from expected in all grades, in most cases $[37,99,100]$.

With regard to COPD patients' treatment adherence, high rates of non-compliance have been documented, as the majority lower the doses of their medication because they are struggling to afford the cost $[13,39,41,100-102]$, while $46 \%$ of patients forget or consciously stop medicating properly [13, 39, 41, 100-102]. Remarkably, despite the fact that health seems to be the last expenditure category for which chronic patients would be willing to decrease spending, one in five patients are forced to reduce spending for their health conditions [102]. More convincingly, according to SKroumpelos et al. [102], patients with COPD report a significant decrease in spending for physician visits (17.5\%), examinations (14.7\%) and COPD drugs (5.8\%) during the crisis.

During the last decade, state-funded pensions have suffered major reductions, while public insurance has increased patients' co-payment percentages from $10 \%$ to $25 \%$ for prescribed medication $[9,11,13]$. Taking into consideration that the majority are current veteran retirees [103] also suffering from other comorbidities [11], medication for chronic conditions such as COPD has become inaccessible for many patients $[11,13,86,103]$. The mean annual cost of treatment for each stable COPD patient has been estimated to be $€ 952.92$, of which $€ 239.91$ has been paid by the patients [13]. The pharmacological cost of treatment for COPD patients seems to be considerable in all disease stages [13, 104], leading to insufficient treatment [87]. Thus, the health of the Greek population is exposed to further risks [87]. Patients omitting taking their drugs were found to have $11.5 \%$ more exacerbations and $14.1 \%$ more hospitalisations annually, and they were more likely to be admitted to an intensive care unit (ICU) [41]. Another phenomenon is the challenge of changing prescribed drugs to generics, otherwise patients have to bear the cost on their own $[13,87,95,102,105]$. Hence, serious adverse events lead to higher costs due to disease complications [13, 106, 107]. However, Miтsiki et al. [35] have reported that newly diagnosed COPD cases present a better compliance to treatment than the known COPD group.

Moreover, having a caregiver at home, which is common practice in Greece, may also improve treatment adherence [87]. Informal caregiving is the major type of home care, with nonfamily members playing a significant role [87]. According to a recent study, carers frequently report that they are unprepared to undertake a proper caring role as they do not initially realise the nature of COPD and its long-term implications [87]. Therefore, a well-planned multidisciplinary cooperation between healthcare professionals and caregivers is more than necessary [87]. 


\section{Economic burden of COPD exacerbations during the Greek crisis}

Disease progression is variable, but acute exacerbations of COPD are debilitating, often trigger hospital admission with major economic consequences, and hasten a progressive decline in pulmonary function [108]. Currently, it has been supported that about half of COPD exacerbations constitute severe exacerbations $[13,106]$, which poses a significant economic burden on society. More specifically, nowadays it is estimated that per severe exacerbation $€ 1711$ will be spent and only $€ 621$ will be reimbursed by social security funds [106]. Additionally, the cost has been shown to increase in a linear fashion in the case of advanced disease (GOLD grades A-D) [41, 106]. Recently it was estimated that the mean cost of an exacerbation for Stage IV patients is approximately $€ 2600$, while for patients at Stages I, II and III it is approximately $€ 1400[99,106,107]$. Combination therapies, as well as the cost of comorbidity-associated management, are the reasons for the large increase in medication expense in this group of patients [106, 107]. Another study estimated the annual per-patient direct costs (including the cost of exacerbations, hospitalisation and pharmaceutical treatment) of COPD to be $€ 2810,54 \%$ of which reflected the management of exacerbations [109]. When indirect (work loss days per year and other productivity losses) and patient time costs were added to direct costs, the total annual burden of COPD in Greece rose sharply to $€ 4730$ per patient [109].

\section{Economic burden of COPD hospitalisations in times of austerity}

The economic burden of the disease increases not only with increasing disease severity and exacerbations, but is also substantially augmented by hospitalisations and especially admissions to ICUs [41, 102]. Greek data during the crisis show that almost half of patients with moderate-to-severe exacerbations required hospitalisation [106, 107]. Furthermore, unregulated self-medication increases the risk of complications, exacerbations and hospitalisation [106, 107].

It has been found that patients with GOLD Stage IV have five-fold higher than expected hospitalisations and nearly three-fold higher risk of admission to the ICU compared to Stage I patients [41]. Mean hospitalisation cost per COPD patient increases slightly with severity of disease [108]. Importantly, a cost ranging from $€ 863$ to $€ 1446$ has been estimated just for hospitalisation due to exacerbation, while the average cost per exacerbation, weighted with the probability of requiring hospitalisation in an ICU, has been estimated to be $€ 209$ [108].

Consequently, the number of comorbidities is also a determinant factor for more hospitalisations and length for stay. Notably, data showed that patients with at least four comorbidities are $78.5 \%$ more likely to have an exacerbation, have 3.2 times more hospitalisations annually, and spend $12.8 \%$ more days in hospital compared with patients with no comorbidities [41]. The same group of patients had 5.5 times higher odds of being admitted into an ICU, and when that happened they spent more days there than patients without comorbidities [41].

\section{Conclusions}

COPD affects humanity with significant economic impact. Countries that are devoid of financial resources face particular challenges in dealing with the disease. The majority of the related literature, concentrating on Greece as a noteworthy case study, demonstrates how economic crisis and austerity measures can affect COPD burden, quality of care and patients' outcomes. In all levels of the healthcare system, economic restrictions have reduced the capacity to prevent, diagnose and treat COPD. In the fight against the disease, it is critical to monitor its burden regarding economic crisis in order to secure that the optimal distribution of state funding will adapt to current health needs.

\section{Acknowledgements}

All authors contributed to the content of this manuscript and to approval of the final version to be submitted.

\section{References}

1 Filippidis FT, Gerovasili V, Man WDC, et al. Trends in mortality from respiratory system diseases in Greece during the financial crisis. Eur Respir J 2016; 48: 1487-1489.

2 Ferrie JE, Shipley MJ, Stansfeld SA, et al. Effects of chronic job insecurity and change in job security on self reported health, minor psychiatric morbidity, physiological measures, and health related behaviours in British civil servants: the Whitehall II study. J Epidemiol Commun Health 2002; 56: 450-454.

3 Ntountoulaki E, Paika V, Papaioannou D, et al. The relationship of the perceived impact of the current Greek recession with increased suicide risk is moderated by mental illness in patients with long-term conditions. J Psychosom Res 2017; 96: 98-105.

4 Virtanen M, Nyberg ST, Batty GD, et al. Perceived job insecurity as a risk factor for incident coronary heart disease: systematic review and meta-analysis. BMJ 2013; 347: f4746.

Vlachadis N, Vrachnis N, Ktenas E, et al. Mortality and the economic crisis in Greece. Lancet 2014; 383: 691. Stuckler D, Basu S, Suhrcke M, et al. The public health effect of economic crises and alternative policy responses in Europe: an empirical analysis. Lancet 2009; 374: 315-323. 
7 Tapia Granados JA. Increasing mortality during the expansions of the US economy, 1900-1996. Int J Epidemiol 2005; 34: 1194-1202.

8 Brenner MH. Relation of economic change to Swedish health and social well-being, 1950-1980. Soc Sci Med 1987; 25: 183-195.

$9 \quad$ Karamanoli E. Financial crisis harms respiratory health in Greece. Lancet Respir Med 2013; 1: 511-512.

10 Kentikelenis A, Karanikolos M, Papanicolas I, et al. Health effects of financial crisis: omens of a Greek tragedy. Lancet 2011; 378: 1457-1458.

11 Kondilis E, Giannakopoulos S, Gavana M, et al. Economic crisis, restrictive policies, and the population's health and health care: the Greek case. Am J Public Health 2013; 103: 973-979.

12 Bonovas S, Nikolopoulos G. High-burden epidemics in Greece in the era of economic crisis. Early signs of a public health tragedy. J Prev Med Hyg 2012; 53: 169-171.

13 Stafyla E, Kerenidi T, Gerogianni I, et al. The pharmacological cost of COPD during Greek economic crisis. Int $J$ Chron Obstruct Pulmon Dis 2017; 12: 461-466.

14 Kyriopoulos II, Zavras D, Skroumpelos A, et al. Barriers in access to healthcare services for chronic patients in times of austerity: an empirical approach in Greece. Int J Equity Health 2014; 13: 54.

15 Zavras D, Zavras AI, Kyriopoulos I-I, et al. Economic crisis, austerity and unmet healthcare needs: the case of Greece. BMC Health Serv Res 2016; 16: 309.

16 Bacigalupe A, Shahidi FV, Muntaner C, et al. Why is there so much controversy regarding the population health impact of the great recession? Reflections on three case studies. Int J Health Serv 2016; 46: 5-35.

17 Bousquet J, Kiley J, Bateman ED, et al. Prioritised research agenda for prevention and control of chronic respiratory diseases. Eur Respir J 2010; 36: 995-1001.

18 López-Campos JL, Tan W, Soriano JB. Global burden of COPD. Respirology 2016; 2: 14-23.

19 Soriano JB, Rodríguez-Roisin R. Chronic obstructive pulmonary disease overview: epidemiology, risk factors, and clinical presentation. Proc Am Thorac Soc 2011; 8: 363-367.

20 Mathers CD, Loncar D. Projections of global mortality and burden of disease from 2002 to 2030. PLoS Med 2006; 3: e442.

21 Ciapponi A, Alison L, Agustina M, et al. The epidemiology and burden of COPD in Latin America and the Caribbean: systematic review and meta-analysis. COPD 2014; 11: 339-350.

22 Zhang X, Holt JB, Lu H, et al. Multilevel regression and poststratification for small-area estimation of population health outcomes: a case study of chronic obstructive pulmonary disease prevalence using the behavioral risk factor surveillance system. Am J Epidemiol 2014; 179: 1025-1033.

23 Diaz-Guzman E, Mannino DM. Epidemiology and prevalence of chronic obstructive pulmonary disease. Clin Chest Med 2014; 35: 7-16.

24 Fukuchi Y, Nishimura M, Ichinose M, et al. COPD in Japan: the Nippon COPD epidemiology study. Respirology 2004; 9: 458-465.

25 Adeloye D, Chua S, Lee C, et al. Global and regional estimates of COPD prevalence: systematic review and meta-analysis. J Glob Health 2015; 5: 020415.

26 Soriano JB. An epidemiological overview of chronic obstructive pulmonary disease: what can real-life data tell us about disease management? COPD 2017; 14: Suppl. 1, S3-S7.

27 Rothnie KJ, Chandan JS, Goss HG, et al. Validity and interpretation of spirometric recordings to diagnose COPD in UK primary care. Int J Chron Obstruct Pulmon Dis 2017; 12: 1663-1668.

28 Gourgoulianis KI, Katikos P, Moraitis M, et al. Chronic bronchitis in rural and industrial areas. Ann Agric Environ Med 2000; 7: 29-31.

29 Tabak C, Feskens EJ, Heederik D, et al. Fruit and fish consumption: a possible explanation for population differences in COPD mortality (the Seven Countries Study). Eur J Clin Nutr 1998; 52: 819-825.

30 Vrachnis N, Iliodromitou Z, Hamos B. The prevalence of chronic obstructive pulmonary disease in Greeks over 55 years. Arch Hellenic Med 1998; 15: 565-570.

31 Tzanakis N, Anagnostopoulou U, Filaditaki V, et al. Prevalence of COPD in Greece. Chest 2004; 125: 892-900.

32 Sichletidis L, Tsiotsios I, Gavriilidis A, et al. Prevalence of chronic obstructive pulmonary disease and rhinitis in northern Greece. Respiration 2005; 72: 270-277.

33 Minas M, Hatzoglou C, Karetsi E, et al. COPD prevalence and the differences between newly and previously diagnosed COPD patients in a spirometry program. Prim Care Respir J 2010; 19: 363-370.

34 Zachariades AG, Zachariadou T, Adamide T, et al. Prevalence of chronic obstructive pulmonary disease in Cyprus: a population-based study. COPD 2012; 9: 259-267.

35 Mitsiki E, Bania E, Varounis C, et al. Characteristics of prevalent and new COPD cases in Greece: the GOLDEN study. Int J Chron Obstruct Pulmon Dis 2015; 10: 1371-1382.

36 Papaioannou AI, Bania E, Alexopoulos EC, et al. Sex discrepancies in COPD patients and burden of the disease in females: a nationwide study in Greece (Greek Obstructive Lung Disease Epidemiology and health ecoNomics: GOLDEN study). Int J Chron Obstruct Pulmon Dis 2014; 9: 203-213.

37 Kourlaba G, Hillas G, Vassilakopoulos T, et al. The disease burden of chronic obstructive pulmonary disease in Greece. Int J Chron Obstruct Pulmon Dis 2016; 11: 2179-2189.

38 Spyratos D, Chloros D, Michalopoulou D, et al. Estimating the extent and economic impact of under and overdiagnosis of chronic obstructive pulmonary disease in primary care. Chron Respir Dis 2016; 13: 240-246.

39 Minas M, Verrou-Katsarou I, Mystridou P, et al. Two-year mortality of patients with COPD in primary health care: an observational study. Int J Gen Med 2012; 5: 815-822.

40 Kotrogianni F, Malli F, Gourgoulianis KI. Underdiagnosis of respiratory diseases during an economic downturn and the need for spirometry as a screening test. J Bras Pneumol 2013; 39: 254-255.

41 Alexopoulos EC, Malli F, Mitsiki E, et al. Frequency and risk factors of COPD exacerbations and hospitalizations: a nationwide study in Greece (Greek Obstructive Lung Disease Epidemiology and health ecoNomics: GOLDEN study). Int J Chron Obstruct Pulmon Dis 2015; 10: 2665-2674.

42 GBD 2015 Chronic Respiratory Disease Collaborators. Global, regional, and national deaths, prevalence, disability-adjusted life years, and years lived with disability for chronic obstructive pulmonary disease and asthma, 1990-2015: a systematic analysis for the Global Burden of Disease Study 2015. Lancet Respir Med 2017; 5: 691-706. 
Ko FW, Hui DSC. Air pollution and chronic obstructive pulmonary disease. Respirology 2012; 17: 395-401. Cohen AJ, Brauer M, Burnett R, et al. Estimates and 25-year trends of the global burden of disease attributable to ambient air pollution: an analysis of data from the Global Burden of Diseases Study 2015. Lancet 2017; 389: 1907-1918.

Paraskevopoulou D, Liakakou E, Gerasopoulos E, et al. Sources of atmospheric aerosol from long-term measurements (5 years) of chemical composition in Athens, Greece. Sci Total Environ 2015; 527-528: $165-178$.

Filippidis FT, Vardavas CI, Loukopoulou A, et al. Prevalence and determinants of tobacco use among adults in Greece: 4 year trends. Eur J Public Health 2013; 23: 772-776.

Karachaliou F, Kostikas K, Pastaka C, et al. Prevalence of sleep-related symptoms in a primary care population their relation to asthma and COPD. Prim Care Respir J 2007; 16: 222-228.

Papastergiou K, Gourgoulianis K. Comorbidity, chronic obstructive pulmonary disease, and acute cardiovascular diseases. Herz 2017; in press [https://doi.org/10.1007/s00059-017-4582-1].

Koulouri A, Roupa Z, Sarafis P, et al. Assessment of health level and socio-economic characteristics of people working in the shipbuilding industry: a control group study. Glob J Health Sci 2015; 7: 154-161.

European Commission. Attitudes of Europeans towards tobacco and electronic cigarettes, Special Eurobaromete 458. http://data.europa.eu/euodp/en/data/dataset/S2146_87_1_458_ENG. Date last updated: March 30, 2017. Date last accessed: August 24, 2017.

Koefoed MM. Spirometry utilisation among Danish adults initiating medication targeting obstructive lung disease. Dan Med J 2015; 62: pii:B5004.

Kanervisto M, Vasankari T, Laitinen T, et al. Low socioeconomic status is associated with chronic obstructive airway diseases. Respir Med 2011; 105: 1140-1146.

Grigsby M, Siddharthan T, Chowdhury MA, et al. Socioeconomic status and COPD among low- and middle-income countries. Int J Chron Obstruct Pulmon Dis 2016; 11: 2497-2507.

Hegewald MJ, Crapo RO. Socioeconomic status and lung function. Chest 2007; 132: 1608-1614.

Sahni S, Talwar A, Khanijo S, et al. Socioeconomic status and its relationship to chronic respiratory disease. $A d v$ Respir Med 2017; 85: 97-108.

Lewer D, McKee M, Gasparrini A, et al. Socioeconomic position and mortality risk of smoking: evidence from the English Longitudinal Study of Ageing (ELSA). Eur J Public Health 2017; 27: 1068-1073.

Gershon A, Campitelli MA, Hwee J, et al. Socioeconomic status, sex, age and access to medications for COPD in Ontario, Canada. COPD 2015; 12: 668-679.

Eisner MD, Blanc PD, Omachi TA, et al. Socioeconomic status, race, and COPD health outcomes. J Epidemio Community Health 2011; 65: 26-34.

Tsara V, Serasli E, Katsarou Z, et al. Quality of life and social-economic characteristics of Greek male patients on long-term oxygen therapy. Respir Care 2008; 53: 1048-1453.

Zavras D, Tsiantou V, Pavi E, et al. Impact of economic crisis and other demographic and socio-economic factors on self-rated health in Greece. Eur J Public Health 2013; 23: 206-210.

Laliotis I, Ioannidis JP, Stavropoulou C. Total and cause-specific mortality before and after the onset of the Greek economic crisis: an interrupted time-series analysis. Lancet Public Health 2016; 1: e56-e65.

ntikelenis A, Karanikolos M, Reeves A, et al. Greece's health crisis: from austerity to denialism. Lancet 2014 383: 748-753

Institute for Health Metrics and Evaluation. GBD Compare Viz Hub. http://viz.healthmetricsandevaluation.org/ gbd-compare/ Date last updated: Oct 2016. Date last accessed: Aug 27, 2017.

Tapia Granados JA, Ionides EL. Population health and the economy: mortality and the great recession in Europe. Health Econ 2017; in press [https://doi.org/10.1002/hec.3495].

Falagas ME, Vouloumanou EK, Mavros MN, et al. Economic crises and mortality: a review of the literature. Int $J$ Clin Pract 2009; 63: 1128-1135.

Bogdanovica I, Godfrey F, McNeill A, et al. Smoking prevalence in the European Union: a comparison of national and transnational prevalence survey methods and results. Tob Control 2011; 20: e4.

Rachiotis G, Barbouni A, Katsioulis A, et al. Prevalence and determinants of current and secondhand smoking in Greece: results from the Global Adult Tobacco Survey (GATS) study. BMJ Open 2017; 7: e013150.

Filippidis FT, Schoretsaniti S, Dimitrakaki C, et al. Trends in cardiovascular risk factors in Greece before and during the financial crisis: the impact of social disparities. Eur J Public Health 2014; 24: 974-979.

Tsiligianni I, Rodríguez MR, Lisspers $\mathrm{K}$, et al. Call to action: improving primary care for women with COPD. NPJ Prim Care Respir Med 2017; 27: 11.

Global Adult Tobacco Survey: Greece 2013. www.who.int/tobacco/surveillance/survey/gats/grc/en/. Date last updated: Oct 26, 2015. Date last accessed: Aug 24, 2017.

Cavelaars AE, Kunst AE, Geurts JJ, et al. Educational differences in smoking: international comparison. BMJ 2000; 320: 1102-1107. from a population-based cancer registry from 1992 to 2013. Tob Induc Dis 2017; 15: 6.

A, Tyrovolas S, Soulis G, et al. The impact of the financial crisis on lifestyle health determin older adults living in the Mediterranean region: the multinational MEDIS study (2005-2015). J Prev Med Public Health 2017; 50: 1-9.

Margerison-Zilko C, Goldman-Mellor S, Falconi A, et al. Health impacts of the Great Recession: a critical review. Curr Epidemiol Rep 2016; 3: 81-91.

Kalousova L, Burgard SA. Unemployment, measured and perceived decline of economic resources: contrasting three measures of recessionary hardships and their implications for adopting negative health behaviors. Soc Sci Med 2014; 106: 28-34.

Childs E, de Wit H. Effects of acute psychosocial stress on cigarette craving and smoking. Nicotine Tob Res 2010 12: 449-453.

Bell DN, Blanchflower DG. Young people and the Great Recession. Oxford Rev Econ Policy 2011; 27: $241-267$. Gallus S, Tramacere I, Pacifici R, et al. Smoking in Italy 2008-2009: a rise in prevalence related to the economic crisis? Prev Med 2011; 52: 182-183. 
Shaw BA, Agahi N, Krause N. Are changes in financial strain associated with changes in alcohol use and smoking among older adults? J Stud Alcohol Drugs 2011; 72: 917-925.

McClure CB, Valdimarsdottir UA, Hauksdottir A, et al. Economic crisis and smoking behaviour: prospective cohort study in Iceland. BMJ Open 2012; 2: e001386.

Asgeirsdottir TL, Corman H, Noonan K, et al. Was the economic crisis of 2008 good for Icelanders? Impact on health behaviors. Econ Hum Biol 2014; 13: 1-19.

Ruhm CJ. Economic conditions and health behaviors: are recessions good for your health? N C Med J 2009; 70 : 328-329.

Tarantilis F, Athanasakis K, Zavras D, et al. Estimates of price and income elasticity in Greece. Greek debt crisis transforming cigarettes into a luxury good: an econometric approach. BMJ Open 2015; 5: e004748.

Cohen S, Lichtenstein E. Perceived stress, quitting smoking, and smoking relapse. Health Psychol 1990; 9: 466-478.

Parrott AC. Does cigarette smoking cause stress? Am Psychol 1999; 54: 817-820.

Walters J. COPD diagnosis, management and the role of the GP. Aust Fam Physician 2010; 39: 100-103.

Mitonas G, Juvana A, Daniil Z, et al. COPD patients' medical care and support in Greece during financial crisis. Int J Gen Med 2016; 9: 401-407.

Eisner MD. Secondhand smoke and obstructive lung disease: a causal effect? Am J Respir Crit Care Med 2009; 179: 973-974.

Kaplan A, Thomas M. Screening for COPD: the gap between logic and evidence. Eur Respir Rev 2017; 26: 160113.

Minas M, Koukosias N, Zintzaras E, et al. Prevalence of chronic diseases and morbidity in primary health care in central Greece: an epidemiological study. BMC Health Serv Res 2010; 10: 252.

Oikonomidou E, Anastasiou F, Dervas D, et al. Rural primary care in Greece: working under limited resources. Int I Qual Health Care 2010; 22: 333-337.

Rachiotis G, Kourousis C, Kamilaraki M. Medical supplies shortages and burnout among Greek health care workers during economic crisis: a pilot study. Int J Med Sci 2014; 11: 442-447.

Karanikolos M, Mladovsky P, Cylus J, et al. Financial crisis, austerity, and health in Europe. Lancet 2013; 381: 1323-1331.

Gouvalas A, Igoumenidis $\mathrm{M}$, Theodorou $\mathrm{M}$, et al. Cost-sharing rates increase during deep recession: preliminary data from Greece. Int J Health Policy Manage 2016; 5: 687-692.

Filippidis FT, Gerovasili V, Millett C, et al. Medium-term impact of the economic crisis on mortality, health-related behaviours and access to healthcare in Greece. Sci Rep 2017; 7: 46423.

Souliotis K, Kani C, Papageorgiou M. Using big data to assess prescribing patterns in Greece: the case of chronic obstructive pulmonary disease. PLoS ONE 2016; 11: e0154960.

Souliotis K, Papageorgiou M, Politi A, et al. Estimating the fiscal effects of public pharmaceutical expenditure reduction in Greece. Front Public Health 2015; 3: 203.

Pappa E, Kontodimopoulos N, Papadopoulos A, et al. Investigating unmet health needs in primary health care services in a representative sample of the Greek population. Int J Environ Res Public Health 2013; 10: 2017-2027. Papala M, Kerenidi N, Gourgoulianis KI. Everyday clinical practice and its relationship to 2010 and 2011 GOLD guideline recommendations for the management of COPD. Prim Care Respir J 2013; 22: 362-364.

Minas M, Dimitropoulos K, Pastaka Ch, et al. Global initiative for chronic obstructive lung disease for chronic obstructive pulmonary disease: GOLD opportunity for lung disorders. Prev Med 2000; 40: 274-277.

Tsiligianni IG, Papadokostakis P, Prokopiadou D, et al. Impact of the financial crisis on adherence to treatment of a rural population in Crete, Greece. Qual Prim Care 2014; 22: 238-244.

Skroumpelos A, Pavi E, Mylona K, et al. The impact of economic crisis on chronic patients' self-rated health, health expenditures and health services utilization. Diseases 2014; 2: 93-105.

Kypraiou A, Sarafis P, Tsounis A, et al. Depression and anxiety in Greek male veterans after retirement. Mil Med 2017; 182: e1639-e1644.

Schoenborn C, Adams P. Health behaviors of adults: United States, 2005-2007. Vital Health Stat 10 2013; 257: $1-184$.

Piette JD, Rosland AM, Silveira MJ, et al. Medication cost problems among chronically ill adults in the US: did the financial crisis make a bad situation even worse? Patient Prefer Adherence 2011; 5: 187-194.

Geitona M, Hatzikou M, Steiropoulos P, et al. The cost of COPD exacerbations: a university hospital-based study in Greece. Respir Med 2011; 105: 402-409.

Stafyla E, Kerenidi T, Gourgoulianis KI. Chronic obstructive pulmonary disease exacerbation frequency and severity. Int J Chron Obstruct Pulmon Dis 2013; 8: 533-535.

Criner GJ, Bourbeau J, Diekemper RL, et al. Prevention of acute exacerbations of chronic obstructive pulmonary disease: American College of Chest Physicians and Canadian Thoracic Society Guideline. Chest 2015; 147: 894-942.

Souliotis K, Kousoulakou H, Hillas G, et al. The direct and indirect costs of managing chronic obstructive pulmonary disease in Greece. Int J Chron Obstruct Pulmon Dis 2017; 12: 1395-1400. 